\title{
ARTERITE TEMPORAL COM COMPROMETIMENTO DAS GLÂNDULAS SALIVARES
}

\author{
LINEU C. WERNECK * \\ AfFonso CoElho *:s
}

A arterite temporal, descrita por Horton em $1932^{10}$, já foi motivo de numerosos registros na literatura mundial. Esta entidade, que atinge particularmente individuos acima de 50 anos, apresenta, como sintoma principal, cefaléia localizada. Usualmente é o clínico geral quem faz o primeiro atendimento e, em algumas ocasiōes, o paciente é encaminhado a neurologista ${ }^{1,2,3,4}$.

Seu diagnóstico não é puramente acadêmico, mas de real importância sob o ponto de vista prático, pois trata-se de processo generalizado cuja evolução pode resultar em danos irreparáveis, tais como amaurose, infarto do miocárdio, trombose periférica e nefropatia difusa $11,12,13,14$.

Tivemos oportunidade de observar um caso no qual a par de lesões arteriais características, existia comprometimento de glândulas salivares, fato que não é assinalado na literatura que tivemos a nosso alcance.

\section{O B S E R A C Ã O}

PS, 62 anos de idade, sexo masculino, branco, dextro, relatava episódios de cefaléia localizada em um único lado da cabeça, que ocorriam por surtos nos últimos 25 anos. Estes episódios se apresentavam em paroxismos, com dor pulsátil, acompanhados de náuseas e vômitos, que duravam em torno de 4-5 horas. O paciente utilizou várias medicaçōes sendo que, nos últimos anos, desistiu de tratamentos, por não surtirem efeito. Desde há alguns meses, o paciente vem apresentando apatia, desejo de morrer, desinteresse pelo trabalho, insônia, diminuição da libido e deficiências de memória em relação a fatos recentes. Trinta dias antes da consulta surgiram dores nas regióes fronto-temporais, pulsáteis, que permaneciam por várias horas. Quinze dias antes da consulta, notou dilatação dos vasos temporais superficiais, que se tornaram dolorosos ao toque e à palpaçāo. Ha 7 dias notou aumento de volume das parótidas sentindo dores nas articulaçōes temporo-mandibulares quando abria a bôca ou mastigava. Negava episódios de artrite mas referia dores musculares difusas ocasionais. Exame físico - Pressāo arterial $120 \times 80 \mathrm{~mm} \mathrm{Hg;} \mathrm{freqüência}$ cardiaca $100 \mathrm{bpm}$; temperatura $36.4 .^{\circ} \mathrm{C}$. Presenca de nódulos nas regiōes frontotemporais. A palpação das artérias temporais superficiais desencandeava dor; estas artérias estavam espessadas e tortuosas, com pulso presente. As glándulas parótidas

Dos Serviços de Neurologia e Anatomia Patológica do Hospital Santa Cru2 (Curitiba, Paraná): * Auxiliar de Ensino na Disciplina de Neurologia, Faculdade de Medicina da Universidade Federal do Parará; ** Chefe do Serviço de Anatomia Patológica do Hospital de Clínicas da Universidade Federal do Paraná. 
c sub-linguaís estavam aumentadas de volume e indolores à palpaçāo. O exame do pescoço, torax, coração, abdomem, extremidades e articulaçōes foi normal. Normal a ausculta da cabeça e do pescoço. Exame neurológico - Idéias despressivas sem. sinais sugestivos de demêncla orgânica. Nervos crantanos normais. Força muscular, tono e coordenaçāo normais. Normais as sensibilidades dolorosa, tactil, vibratória, de posição segmentar e estereognosia. Nistagmo optocinético normal. Marcha normal. Reflexos profundos normais; ausência de reflexos patológicos. Exames complementares - Hemoglobina 14,5gr/100ml; hematócrito 45\%: 7900 leucócitos por $\mathrm{mm}^{3}$ (eosinófilos $1 \%$, basófilos $2 \%$, linfócitos $10 \%$, monócitos $9 \%$, bastonetes $11 \%$, segmentados $67 \%$ ); plaquetas normais. Exame parcial de urina: traços de proteinas e raras hemácias por campo. No sangue: creatinina $0,8 \mathrm{mg} / 100 \mathrm{ml}$; uréla $32 \mathrm{mg} / 100 \mathrm{ml}$; amilase 60 unidades Somogyl; VHS $60 \mathrm{~mm}$ la hora e $79 \mathrm{~mm}$ na 2 . hora; mucoproteinas $11,31 \mathrm{mg}$ de tirosina $/ 100 \mathrm{ml}$; proteina $\mathrm{C}$ reativa +++ de precipitado. Pesquisa de células L.E. negatíva. Reação do latex negativa. Eletroforese: proteinas totais $5,80 \mathrm{gr} / 100 \mathrm{ml}$; albumina 2,45gr/100ml; globulina alfa-1 $0,47 \mathrm{gr} / 100 \mathrm{ml}$; globulina alfa-2 $1,08 \mathrm{gr} / 100 \mathrm{ml}$; globulina beta $0,88 \mathrm{gr} / 100$; globulina gama $0,92 \mathrm{gr}_{1} / 100 \mathrm{ml}$. Radiografias do crânio e torax normais. Eletrocardiograma normal. A biopsia da artéria temporal superficial esquerda * mostrou tecido muscular estriado e conjuntivo fibroso; nas paredes da artéria e na adventícia existiam focos de necrose e infiltrados inflamatórios (linfócitos, histiócitos e plasmócitos) e, ocasionalmente, células gigantes multinucleadas. As luzes arteriais freqüentemente estavam obliteradas por fibrina e elementos figurados. A túnica elástica interna apresentava-se espessada, descontínua, ocasionalmente duplicada e envolvida pelo processo inflamatório (Fig. 1).

Fol iniciada a terapêtica com Prednisona $40 \mathrm{mg} / \mathrm{dla}$, acido acetilsalicilico e diazepínicos. Em 5 dias a cefaléla cessou completamente e as glândulas salivares voltaram ao normal, tendo desaparecido as dores nas articulações temporo-mandibulares. O estado mental melhorou, desaparecendo a me!ancolia; o humor melhorou, bem como o apetite. Desapareceu a insônia. Em seguimentos ulteriores, o vHS foi para $25 \mathrm{~mm}$ na la hora e $60 \mathrm{~mm}$ na segunda. As mucoproteinas baixaram para 9,7 mg tirosina $100 \mathrm{ml}$ e a proteina $\mathrm{C}$ reativa tornou-se negativa. Os nódulos subcutâneos e vasos entumescidos desapareceram, bem como a dor à palpação.

Dois meses após recebemos informaçōes dos famillares de que o paciente estava apresentando "certas idéias fixas, pensando que ficaria paralitico", sendo sugerido internamento em hospital psiquiátrico, o que fol recusado. Doze dias após fomos informados que o paciente havla se suicidado por afogamento. Necrópsia não foi realizada.

\section{COMENTARIOS}

Em 1932, Horton e col. ${ }^{10}$ descreveram a arterite temporal, correlacionando os achados clínicos com os histopatológicos (inflamação granulomatosa das túnicas média e intima, fragmentação da lâmina interna, ocasional presença de células gigantes e obliteração esparsa do lumem dos vasos). No entantanto, em outras revisões foi verificado que as células gigantes estavam ausentes, apresentando-se a entidade como uma arterite inespecífica ${ }^{6}$.

Além das manifestações citadas por Horton e col., foram sendo relatados cnvolvimentos de outras artérias, tais como aorta e seus ramos, coronárias, iliacas e renais $11,12,13,14$.

- A biopsia da artéria temporal fol feita pelo Dr. José Faria Ratton, do Servico de Neurocirurgia do Hospital Santa Cruz, ao aual agradecemos a colaboração. 

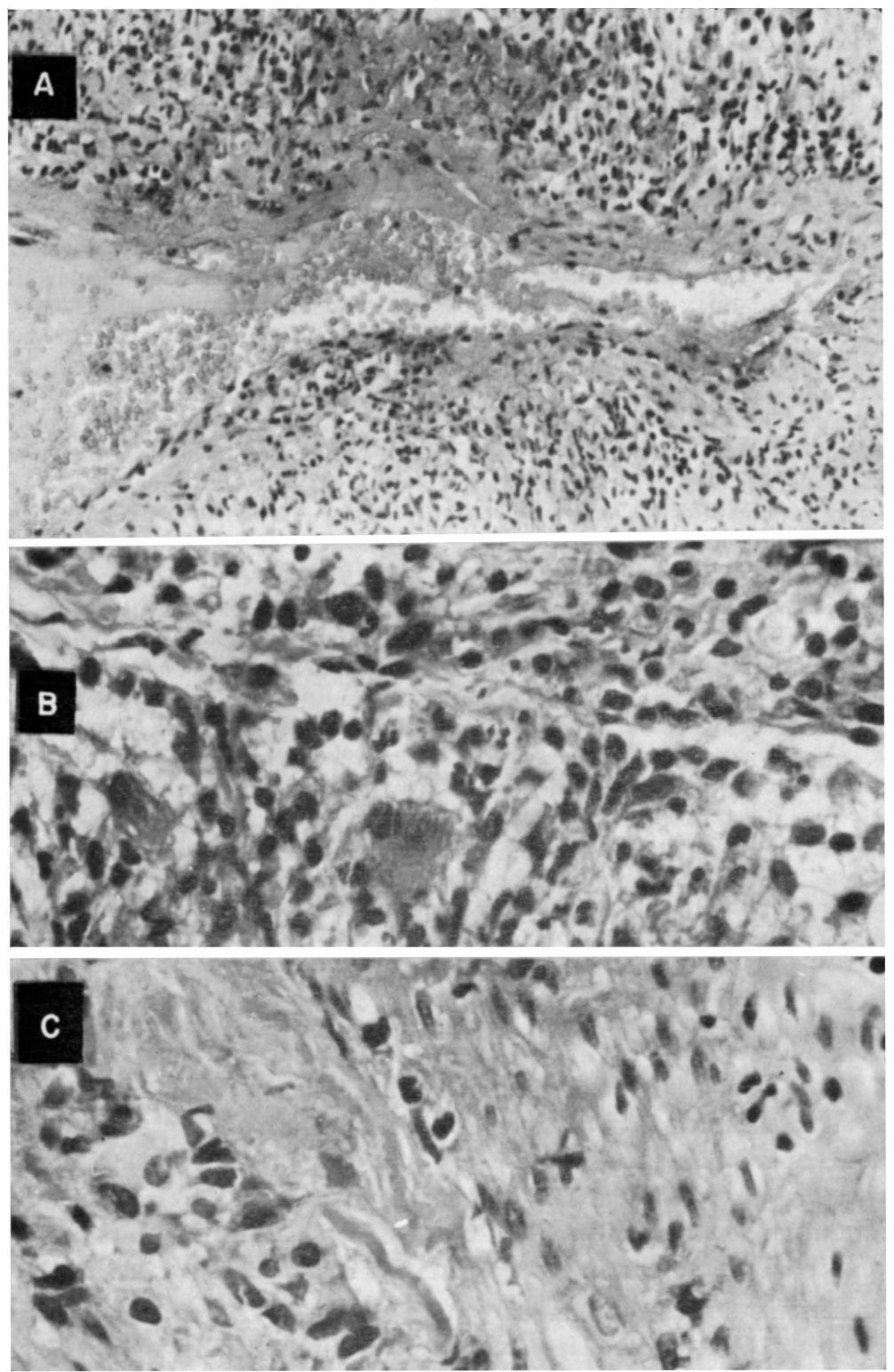

Fig. 1 - Em A, infiltrado em parede arterial e adventícia com células gigantes ( $H E$ 100x); em $B$, infiltrado em parede arterial com células gigantes ( $H E$ 450x); em $C$, espessamento da elastica interna $e$ inflamação envolvente ( $H E$ 450x). 
Recentemente a arterite temporal foi correlacionada com a polimialgia reumática devido à grande incidência das duas condições no mesmo indivíduo ${ }^{5}$. A polimialgia reumática é uma entidade que ocorre a partir da 5.* década, caracterizando-se por dores musculares agudas, enrigecimento das articulações, com dor à mobilização, aumento da velocidade de eritrossedimentação, sendo admitido que a base anatômica da entidade seja constituída por arterite muscular difusa. Apesar do grande número de casos estudados, ainda não há conclusão definitiva quanto à etiologia da arterite temporal. No momento ela é considerada doença autoimunitária, sendo comumente relacionada entre as doenças do colágeno ${ }^{15}$.

Não conseguimos encontrar na literatura referência a envolvimento de glândulas salivares nesta entidade, como o nosso paciente apresentou. Podemos inferir por comparação com as outras doenças do colágeno que estaria se desenvolvendo uma síndrome de Sjögreen. No entanto, a pronta administração de corticoesteróides interrompeu a evolução natural.

A partir de 1957, com a introdução terapêutica de ACTH e corticoesteróides ${ }^{3}$ no tratamento da arterite temporal, o curso natural da doença foi mudado, apesar de ser uma entidade auto-limitada e esta tem sido a sua terapêutica até os dias atuais.

Não temos condições para avaliar até onde a terapêutica teve implicação no desenlace fatal do nosso caso. No entanto, a sindrome depressiva aparentemente faz parte do quadro clínico, sendo que, na maioria das vezes, precede a sintomatologia dolorosa ${ }^{2}$. Esta depressão estava presente no nosso paciente, evidenciada tanto pelo conteúdo de seus pensamentos, bem como pelos equivalentes orgânicos da mesma, sendo de estranhar que não tenha havido melhora do quadro psiquiátrico, como relatam os trabalhos publicados anteriormente ${ }^{1,6}$. Não encontramos referência na literatura com respeito ao suicídio.

No Brasil, encontramos relatos em 1949, por Arnaldo Marques e col. ${ }^{7}$. A seguir em 1957, Ackerman e col. ${ }^{8}$ descreveram 5 casos com sintomatologia típica de arterite temporal, sendo comprovado o diagnóstico mediante biopsia em dois pacientes. Em 1968 Wolosker e col. ${ }^{9}$ estudaram outro caso, apresentando revisão bibliográfica.

No presente caso, devem ser realçados o aumento de glândulas salivares e a severidade da síndrome depressiva que levou o paciente ao suicidio. Estes fatos não foram assinalados nos trabalhos que pudemos compulsar. Para concluir, acreditamos que todo paciente com idade superior a 50 anos, cuja doença inicie com cefaléia ou no qual cefaléias pré-existentes sofram alterações em sua apresentação clínica, justifica investigação no que tange a doenças inflamatórias do colágeno.

R ES U M O

E relatado um caso de arterite temporal em paciente com crises de cefaléia paroxística associadas a síndrome depressiva e, na última crise, a aumento de volume das glândulas salivares. Biopsia de artéria temporal 
superficial mostrou aspecto típico de arterite, com células gigantes mononucleadas. A cefalalgia e o aumento de volume das glândulas salivares regrediram mediante a administração de corticoesteróides.

\section{S U M M A R Y}

Temporal arteritis associated with salivary glands enlargement and depressive syndrome: a case report.

A case of temporal arteritis associated with depressive syndrome and enlargement of salivary glands is reported. Biopsy of the superficial temporal artery showed arteritis with multinucleated giant cells. After corticosteroid therapy the headache and the enlargement of the salivary gland improved rapidly.

\section{R E F E R E N I A S}

1. ANDREWS, J. M. - Giant-cell (temporal arteritis), a disease with variable clinical manifestations. Neurology (Minneapolis) 16:963, 1966.

2. KNORRING, J. V.; ERMA, M. \& LINDSTROM, B. - The clinical manifestations of temporal arteritis. Acta Med. Scandinavica 179:691, 1966.

3. BIRKHEAD, N. C.; WAGENER, H. P. \& SHICK, R. M. - Treatment of temporal arteritis with adrenal corticosteroids. J.A.M.A., 163:821, 1957.

4. HOLLENHORST, R. W.; BROWN, J. R.; WAGENER, H. P. \& SHICK, R. M. Neurologic aspects of temporal arteritis. Neurology (Minneapolis) 10:490, 1960.

5. HAMILTON, C. R.: SHELLEY, W. M. \& TUMULTY, P. A. - Giant cell arteritis including temporal arteritis and polymialgia rheumatica. Medicine 50:1, 1971.

6. PAUlleY, J. W. \& HUGHS, J. P. - Giant cell arteritis or arteritis of the aged. Brit. Med. J. 2:1562, 1960.

7. MARQUES, A.: MORAIS, J, \& VILANOVA, N. - O sindromo clínico da arterite temporal de Horton. Brasil Méd. (Rio de Janeiro) 63:255, 1949.

8. ACKERMAN. A.; BARRETO NETO \& NIEMEYER, P. - Arterite de células gigantes. Med. Cirurgia e Farm. (Rio de Janeiro) n.o 252:117, 1957.

9. WOLOSKER, M.; KAUFMAN, P.; MURACO, B.; WAIMANN, J. T. \& LEAO L. E. P. - Arterite temporal. Rev. Hosp. Clínicas Fac. Med. Univ. São Paulo 23:267, 1968 .

10. HORTON, B. T.; MAGATH, T. B. \& BROWN, C. E. - Undescribed form of arteritis of temporal vessels. Proc. Staff Meet. Mayo Clin. 7:700, 1932.

11. GILMOUR, J. R. - Giant-cell chronlc arteritis. J. Path \& Bact. 53:263, 1941.

12. COOKE, W.T.; CLOAKE, P. C. P.; GOVAN, A. D. T. \& COLBECK, J. C. - Temporal arteritis: a generalized vascular disease. Quart. J. Med. 15:47, 1946.

13. CARDELL, B. S. \& HANLEY, T. - A fatal case of glant-cell or temporal arteritis. J. Path. \& Bact. 63:587, 1951.

14. HEPTINSTALL, R. H.; PORTER, K. A. \& MARKLEY, H. - Giant-cell (temporal) arteritis. J. Path. \& Bact. 67:507, 1954.

15. POLASKI, N.; POLASKI, S.; MOGENHEIN, H. \& ABRAM, N. R. - Giant-cell arteritis. J.A.M.A. 191:341, 1965.

Hospital Santa Cruz - Serviço de Neurologia - Rua do Rosário $114-80000$ Curitiba, PR - Brasil. 